\title{
Earthquake early warning in Aotearoa New Zealand: a survey of public perspectives to guide warning system development
}

\author{
Julia S. Becker (1) ${ }^{1 凶}$, Sally H. Potter ${ }^{2}$, Lauren J. Vinnell (1) ${ }^{1}$, Kazuya Nakayachi (D) ${ }^{3}$, Sara K. McBride ${ }^{4} \&$ \\ David M. Johnston ${ }^{1}$
}

Earthquake early warning (EEW) can be used to detect earthquakes and provide advanced notification of strong shaking, allowing pre-emptive actions to be taken that not only benefit infrastructure but reduce injuries and fatalities. Currently Aotearoa New Zealand does not have a nationwide EEW system, so a survey of the public was undertaken to understand whether EEW was considered useful and acceptable by the public, as well as perceptions of how and when such warnings should be communicated, before making an investment in such technology. We surveyed the public's perspectives $(N=3084)$ on the usefulness of EEW, preferred system attributes, and what people anticipated doing on receipt of a warning. We found strong support for EEW, for the purposes of being able to undertake actions to protect oneself and others (e.g. family, friends, and pets), and to mentally prepare for shaking. In terms of system attributes, respondents expressed a desire for being warned at a threshold of shaking intensity MM5-6. They suggested a preference for receiving a warning via mobile phone, supported by other channels. In addition to being warned about impending shaking, respondents wanted to receive messages that alerted them to other attributes of the earthquake (including the possibility of additional hazards such as tsunami), and what actions to take. People's anticipated actions on receipt of a warning varied depending on the time available from the warning to arrival of shaking. People were more likely to undertake quicker and easier actions for shorter timeframes of $<10 \mathrm{~s}$ (e.g., stop, mentally prepare, take protective action), and more likely to move to a nearby safe area, help others, look for more information, or take safety actions as timeframes increased. Given the public endorsement for EEW, information from this survey can be used to guide future development in Aotearoa New Zealand and internationally with respect to system attributes, sources, channels and messages, in ways that promote effective action.

\footnotetext{
${ }^{1}$ Joint Centre for Disaster Research, Massey University, PO Box 756, Wellington 6140, New Zealand. ${ }^{2}$ GNS Science, P.O. Box 30368, Lower Hutt 5040, New Zealand. ${ }^{3}$ Faculty of Psychology, Doshisha University, 1-3, Miyakodani, Tatara, Kyotanabe-shi, Japan. ${ }^{4}$ United States Geological Survey, 345 Middlefield Road, MS 977, Menlo Park, CA 94025, USA. ${ }^{凶}$ email: j.becker@massey.ac.nz
} 


\section{Introduction}

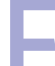
arthquake early warning (EEW) is becoming more utilised around the world. EEW systems are designed to detect earthquakes at their source or detect the arrival of P-waves before shaking from the S-waves arrives (Given et al., 2018). After detection, a warning notification is sent out to locations that can expect shaking. This notification may give anywhere from a few seconds to two minutes warning before shaking occurs. If a location is close to the epicentre of an earthquake, it will not likely receive a warning prior to the shaking arriving. Additionally, the amount of warning time available and the eventual shaking intensities felt, depend on the nature of the fault rupture that produces the earthquake. Even though longer warning times are possible, many places are only likely to get $<10 \mathrm{~s}$ warning of strong shaking (Minson et al., 2018).

EEWs are beneficial, as they allow organisations to take either automated or procedural actions to counter the impacts of the shaking. Examples of organisational actions include slowing trains, stopping surgeries, or turning off dangerous or essential equipment (Johnson et al., 2016; Allen and Melgar, 2019). A warning can also give employees and the public enough time to take protective actions such as moving away from dangerous areas or performing the 'drop, cover and hold' action. Consequently, EEWs have the potential to reduce damage, minimise injuries and save lives (Sutton et al., 2020).

A number of countries have functioning EEW systems including Japan, Taiwan, South Korea, Mexico, and the USA (Allen and Melgar, 2019). Every country's system is slightly different-some countries have national systems of sensors, some use stand-alone alerting devices (often networked), and others rely on a combination of both. The source, channels and messages provided for the warnings also differ depending on the country context.

In Aotearoa New Zealand, EEW is still in its infancy, with no comprehensive national system in place. While some countries have undertaken research on organisational uses of EEW before system development (e.g. USA (Goltz, 2001; Johnson et al., 2016); Mexico (Espinosa-Aranda et al., 2011); Japan (Horiuchi, 2009; Hoshiba, 2014); various European nations (Clinton et al., 2016)) and recently in New Zealand (Becker et al., 2020)), exploratory research on public utility of earthquake warnings has rarely been undertaken before developing EEW technology. Consequently, we took a different approach; using surveys to investigate whether EEW is considered useful and worth the investment by the public.

As New Zealand has limited experience of EEW, the researchers looked to Japan, where a national EEW system has been officially operated by the Japan Meteorological Agency (JMA) since 2007 (Fujinawa and Noda, 2013). Given many years of public exposure to EEWs and limited research on people's response to these warnings, we, the authors, sought to understand how the Japanese public react by undertaking two public surveys following warnings for earthquakes that occurred in Gunma and Chiba Prefectures in 2018 (Nakayachi et al., 2019). While the aim of these surveys was to better understand how the Japanese public responds to EEWs, it also had a secondary purpose of developing questions for a survey in New Zealand.

Using the Japan survey questions (Nakayachi et al., 2019) as a starting point, we modified the survey for the New Zealand context. In the survey we sought to understand the public's perspectives on whether an EEW system would be useful for New Zealand. We asked about their preferences for such a system, including desired warning thresholds, response timeframes, channel for receiving a warning, and message preferences. To understand people's likely behavioural response to an EEW, we also used a hypothetical scenario to enquire about what people anticipated doing on receipt of a warning. This scenario was based on similarities to the real EEWs experienced by Gunma and Chiba Prefectures in 2018. Our paper presents the survey data and provides a commentary on how these data might inform future directions for EEW, both in New Zealand and internationally.

\section{Methodology}

We chose to use a survey to collect empirical data on people's perspectives about EEW, situating our research primarily in a positivist philosophy, with a deductive approach (Melnikovas, 2018). Survey data is useful as it can provide an overview of people's thoughts and actions, is generalisable across populations, and can be applied to existing theoretical frameworks. Both the Japan and New Zealand surveys were developed based on published theoretical research on people's behaviour to warnings (Mileti and Sorensen, 1990; Goltz, 2001; Lindell and Perry, 2012; Dunn et al., 2016; Wood et al., 2017). Aspects that informed our EEW questions included: the importance of information receipt, interpretation and confirmation; previous experience of events; threat perceptions and perceptions of protective action; the effect of biases (e.g. optimism bias); environmental and social influences on the warning process; trust in warnings; and the availability of personal resources (including self- and response-efficacy, and practical skills gained through undertaking earthquake preparedness activities and exercises).

\section{Materials}

For the New Zealand survey we adapted the Japanese questions for relevance to the cultural context and added others about warning content and timeframes. The New Zealand survey contained 20 questions in total, with18 quantitative (single response, multiple response, and Likert scale) and 2 qualitative (free response) questions (see Supplementary Information). The questions focused on previous earthquake experience, anticipated behavioural response to EEWs (within the context of a hypothetical scenario based on the 2018 Gunma and Chiba earthquakes), reasons for those anticipated responses, perceived usefulness of EEWs, preferred attributes of a warning system (i.e., warning thresholds, timeframes, channels, and messages), earthquake preparedness, and demographics.

We followed Massey University of Aotearoa New Zealand human ethics procedures and our research was deemed to be low risk, resulting in the submission of a Low-risk Human Ethics Notification (Ethics Notification Number: 4000019302). The survey ran online via SurveyMonkey from 22 March 2019 to 30 April 2019. The survey was promoted by press release (resulting in a newspaper article in a national paper and radio interviews) and social media (e.g. Facebook, Twitter).

Data. We received a total of 3084 responses from across New Zealand. Basic frequency analyses were undertaken using the SPSS and Excel software programmes, and frequency tables showing percentages were constructed from the quantitative data. Tests of significance were undertaken, but are not reported in this paper, and will be focus of future work. Themes were coded from the free-response qualitative data and analysed using methods recommended by Corbin and Strauss (2014). Quotes reflecting these themes are presented throughout this paper. Given we had over 3000 respondents, the themes for Question 15, which asked about people's anticipated responses for different warning timeframes, were also further organised into categories and analysed quantitatively (see section "Warning time versus actions"). 
Participants. Large numbers of responses came from the regional areas of Auckland, Canterbury, East Coast North Island (Hawke's Bay/Gisborne), Wellington, and Otago/Southland (Table 1). Respondents were more likely than average to be female (65\%) and to consider their ethnicity to be New Zealander (40\%) or New Zealand European (46\%). Males (33\%) and other specific ethnic identities, including Māori (4\%), were underrepresented in the survey. A range of people from different age groups filled out the survey (Table 1) similar to the age profile of New Zealand where the median age is 37.4 years and $\sim 45 \%$ of the population is between 30 and 64 years (NZ.Stat., n.d.).

Limitations. The gender and ethnicity bias in the data pose potential limitations. Previous work exploring the role of demographics in earthquake preparedness behaviour suggests mixed impact of such biases. For example, some researchers have found gender to influence earthquake preparedness (Mulilis, 1999), while others suggest demographics has only limited impact on the preparedness process (Becker et al., 2015). In addition to demographic bias, the survey self-selection process might mean the

Table 1 Location and demographic characteristics of the EEW survey participants.

\begin{tabular}{|c|c|c|c|c|c|}
\hline \multicolumn{2}{|c|}{ Location $\%(N=2545)^{a}$} & \multicolumn{2}{|c|}{ Gender \% $(N=2572)$} & \multicolumn{2}{|l|}{$\begin{array}{l}\text { Age \% } \\
(N=2566)\end{array}$} \\
\hline Auckland & 9 & Male & 33 & $18-20$ years & 3 \\
\hline Bay of Plenty & 3 & Female & 65 & $21-29$ years & 12 \\
\hline Canterbury & 29 & Transgender female & $<1$ & $30-39$ years & 23 \\
\hline Gisborne & 1 & Transgender male & $<1$ & 40-49 years & 24 \\
\hline Hawke's Bay & 5 & Gender diverse & $<1$ & $50-59$ years & 19 \\
\hline $\begin{array}{l}\text { Manawatu- } \\
\text { Wanganui }\end{array}$ & 5 & Decline to answer & 1 & $60-69$ years & 13 \\
\hline Marlborough & 2 & & & $70-79$ years & 5 \\
\hline Nelson & 2 & & & $80+$ years & 1 \\
\hline Northland & 1 & \multirow{2}{*}{\multicolumn{2}{|c|}{ Ethnicity \% $(N=3084)$}} & & \\
\hline Otago & 5 & & & & \\
\hline Southland & 1 & \multicolumn{2}{|l|}{ New Zealander } & \multicolumn{2}{|l|}{40} \\
\hline Taranaki & 2 & \multicolumn{2}{|c|}{ New Zealand European } & \multicolumn{2}{|l|}{46} \\
\hline Tasman & 1 & \multicolumn{2}{|l|}{ New Zealand Māori } & \multicolumn{2}{|l|}{4} \\
\hline Waikato & 3 & \multicolumn{2}{|l|}{ Pacific Islander } & \multicolumn{2}{|l|}{1} \\
\hline Wellington & 31 & \multicolumn{2}{|l|}{ Asian } & \multicolumn{2}{|l|}{1} \\
\hline West Coast & 1 & \multicolumn{2}{|l|}{ Decline to answer } & \multicolumn{2}{|l|}{1} \\
\hline & & \multicolumn{2}{|l|}{ Other (please specify) } & \multicolumn{2}{|l|}{7} \\
\hline
\end{tabular}

survey was answered by people with more interest or experience in earthquake hazards, skewing the answers toward a position of greater knowledge. Use of a hypothetical scenario may have influenced participants' answers about their intended responses, and preferred attributes of a warning system. Finally, the survey might also have been impacted by social desirability bias (Phillips and Clancy, 1972) whereby respondents answered questions in ways they thought favourable to the researchers to appear more compliant with social norms. Consequently, EEW survey responses should be interpreted in the context of potential demographic, personal and contextual biases.

\section{Results and discussion}

Usefulness of EEW. Overall, respondents were supportive of having an EEW system. Nearly $97 \%$ thought that a system would be either "Useful" (76\%) or "Somewhat useful" (19\%). These results are similar to those from Japan and Mexico where somewhere between $64-75 \%$ of the public in those countries perceive their EEW systems to be useful, despite experiencing occasional false or missed alarms (Nakayachi et al., 2019; SantosReyes, 2019). Reasons New Zealanders thought that EEW would be useful included that they could prepare for physical actions they needed to take $(91 \%)$ including protecting themselves $(79 \%$; aligning with $75 \%$ in a previous USA study (Dunn et al., 2016) and helping or saving others nearby (79\%; Table 2). Interestingly, as per the Japanese experience, New Zealanders were also very supportive of the fact that EEW could help them mentally prepare for impending shaking. The percentage of support for this benefit was identical to results from the Japanese study (83\%), confirming support for EEW's value for psychological preparedness. In the "Other" category (6\%) there were also some unique reasons people gave as qualitative comments for supporting EEW including a focus on ensuring a warning would be given to essential services $(n=17)$, assessing tsunami risk $(n=15)$, and protecting pets $(n=14)$.

Of the small proportion $(3 \%, n=87)$ who thought EEW would be "Somewhat useless" or "Useless", their primary reason related to the fact that they might not be able to react to a warning in time (59\%), a reason not shared as strongly by Japanese participants. In Japan only a third or less of people from both Gunma and Chiba prefectures who had experienced a real EEW indicated that they had been unable to respond to the warnings they had received (Nakayachi et al., 2019-see also Table 3). In contrast, Japanese participants were more likely to think that EEW might be useless because they might not have received a warning for past earthquakes until after the shaking had started

Table 2 Reasons why New Zealand respondents thought EEW would be useful, compared with Japan respondents (Nakayachi et al., 2019, p.11).

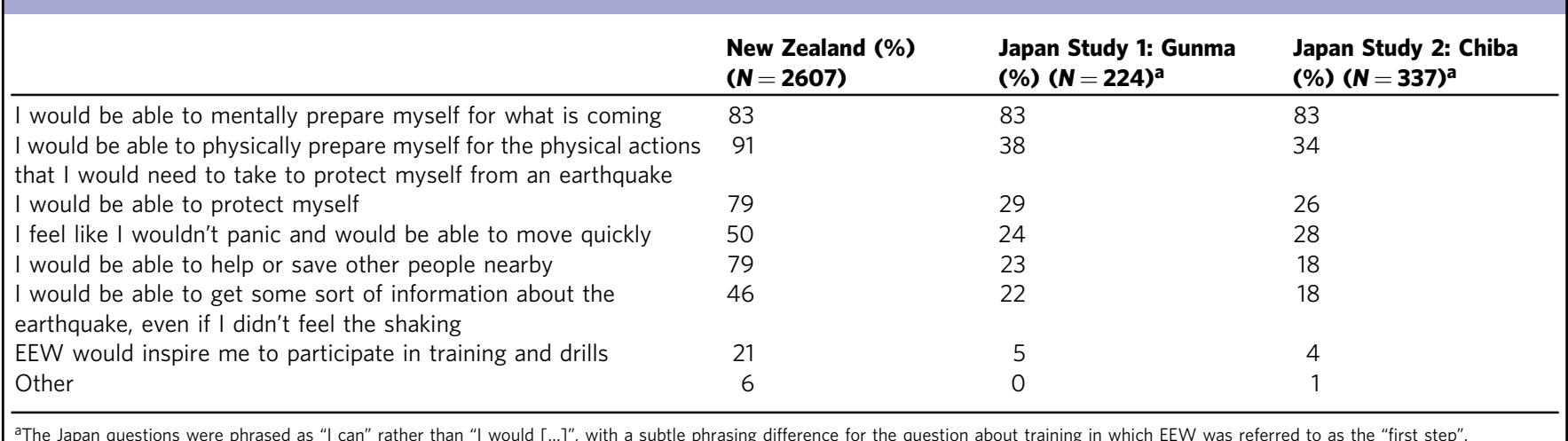


Table 3 Reasons why respondents thought EEW might be useless, compared with Japan respondents (Nakayachi et al., 2019, p.11).

\begin{tabular}{|c|c|c|c|}
\hline & $\begin{array}{l}\text { New Zealand }(\%) \\
(N=87)\end{array}$ & $\begin{array}{l}\text { Japan Study 1: Gunma (\%) } \\
(N=75)^{a}\end{array}$ & $\begin{array}{l}\text { Japan Study 2: Chiba (\%) } \\
(N=113)^{\mathrm{a}}\end{array}$ \\
\hline $\begin{array}{l}\text { I might receive a warning after the shaking has started, and not } \\
\text { be able to respond }\end{array}$ & 53 & 68 & 64 \\
\hline $\begin{array}{l}\text { The message might say 'strong shaking', but in reality the } \\
\text { shaking might be very small }\end{array}$ & 39 & 13 & 12 \\
\hline $\begin{array}{l}\text { Despite receiving an EEW, I might not experience any shaking } \\
\text { occurring afterward }\end{array}$ & 31 & 8 & 6 \\
\hline I might not notice it (i.e. not see or hear the warning) & 51 & 5 & 6 \\
\hline I would not know what to do if I received an alert & 6 & Not asked in Japan & Not asked in Japan \\
\hline $\begin{array}{l}\text { The people around me would not know what to do and I would } \\
\text { have to help them }\end{array}$ & 8 & Not asked in Japan & Not asked in Japan \\
\hline
\end{tabular}

Table 4 The New Zealand Modified Mercalli (MM) intensity shaking scale (from GeoNet (Geonet, n.d. b), based on Dowrick (1996)).

\begin{tabular}{|c|c|c|}
\hline $\mathbf{M M}$ & Intensity & Description \\
\hline 1 & Unnoticeable & Barely sensed only by a very few people. \\
\hline 2 & Unnoticeable & Felt only by a few people at rest in houses or on upper floors. \\
\hline 3 & Weak & Felt indoors as a light vibration. Hanging objects may swing slightly. \\
\hline 4 & Light & $\begin{array}{l}\text { Generally noticed indoors, but not outside, as a moderate vibration or jolt. Light sleepers may be awakened. Walls may creak, } \\
\text { and glassware, crockery, doors or windows rattle. }\end{array}$ \\
\hline 5 & Moderate & $\begin{array}{l}\text { Generally felt outside and by almost everyone indoors. Most sleepers are awakened and a few people alarmed. Small objects } \\
\text { are shifted or overturned, and pictures knock against the wall. Some glassware and crockery may break, and loosely secured } \\
\text { doors may swing open and shut. }\end{array}$ \\
\hline 6 & Strong & $\begin{array}{l}\text { Felt by all. People and animals are alarmed, and many run outside. Walking steadily is difficult. Furniture and appliances may } \\
\text { move on smooth surfaces, and objects fall from walls and shelves. Glassware and crockery break. Slight non-structural damage } \\
\text { to buildings may occur. }\end{array}$ \\
\hline 7 & Severe & $\begin{array}{l}\text { General alarm. People experience difficulty standing. Furniture and appliances are shifted. Substantial damage to fragile or } \\
\text { unsecured objects. A few weak buildings are damaged. }\end{array}$ \\
\hline 8 & Extreme & Alarm may approach panic. A few buildings are damaged and some weak buildings are destroyed. \\
\hline 9 & Extreme & Some buildings are damaged and many weak buildings are destroyed. \\
\hline 10 & Extreme & Many buildings are damaged and most weak buildings are destroyed. \\
\hline 11 & Extreme & Most buildings are damaged and many buildings are destroyed. \\
\hline 12 & Extreme & All buildings are damaged and most buildings are destroyed. \\
\hline
\end{tabular}

(Study 1 Gunma: 68\%; Study 2 Chiba 64\%; New Zealand 53\%). New Zealanders additionally thought that EEW effectiveness might be questionable because they might not notice a warning $(51 \%)$, or despite receiving a warning that says "strong shaking" might only receive minor shaking $(39 \%)$ or no shaking at all (31\%). In the "Other" category (30\%) some responses purported that EEW was a waste of time $(n=13)$ while one person highlighted that patchy mobile phone coverage might prove an issue for effective warning in New Zealand.

\section{Preferred attributes of a warning system}

Modified Mercalli intensity thresholds. New Zealand has its own Modified Mercalli (MM) intensity shaking scale (Dowrick, 1996). Participants reported the minimum level of MM intensity for which they thought a warning would be useful. They were provided with a table showing the descriptions for MM3-MM8+ (Table 4) along with a cartoon picture from GeoNet Felt Rapid that reflects each level (Haubrock et al., 2017; GeoNet, n.d. a) and were asked to select their preferred minimum intensity. The most popular intensity level was MM5 or moderate shaking (51\%) followed by MM6 or strong shaking (25\%) (Table 5).

Because MM scales vary internationally, it is difficult to tell whether the most popular choices of category for the New Zealand survey align with thresholds already used for warnings in other countries. New Zealand MM5-6 potentially aligns with thresholds for public warnings in places like Japan $(5 \mathrm{~L}$ on the Japanese intensity scale, strong shaking (Nishimae, 2018)) but appears to be slightly higher than the MM thresholds used in the USA. Previously US thresholds have been identified as MMI 4 (light shaking: the threshold for light building damage) (Given et al., 2018), however debate has recently arisen following the 2019 Ridgecrest earthquake in California, about lowering thresholds for alerting the public to US MMI 3. Public who felt the shaking but did not receive a warning due to a higher threshold 
Table 5 Minimum MM intensity levels for warnings suggested by respondents.

\section{MM level}

MM3

MM4

MM5

MM6

MM7

$\mathrm{MM} 8-\mathrm{MM} 12$

$\%(\mathbf{N}=\mathbf{2 5 9 3})$

Table 6 Minimum amount of time respondents felt they needed to undertake a response to the warning presented in the scenario.

\section{Time}

$0-2 \mathrm{~s}$ or simultaneously

$3-5 s$

$6-10 \mathrm{~s}$

$11-20 \mathrm{~s}$

$21-30 \mathrm{~s}$

$31-60 \mathrm{~s}$

$61-90 \mathrm{~s}$

$91-120 \mathrm{~s}$

suggested a desire to be notified about large earthquakes even with low shaking intensities at certain locations (Cochrane and Husker, 2019).

Our data suggests that the public support higher alerting thresholds; however, this is within a New Zealand specific context where $73 \%$ of participants had experienced strong shaking previously (e.g. 2010-2011 Canterbury earthquakes) and where there is no operating EEW infrastructure. It is possible that influences such as previous experience, individual perspectives, and social and environmental factors may place additional demands on threshold setting.

Minimum warning time needed to respond. We asked survey participants the minimum time that they would need to undertake a response to the warning (i.e., between receiving an alert and feeling the shaking). Interestingly, we received a wide range of responses to this question. Few people (2\%) felt they could do anything with $0-2 \mathrm{~s}$ of warning. The greatest proportion of people $(21 \%)$ felt that $6-10 \mathrm{~s}$ of warning was the minimum time needed, similar to what is reported in an EEW study by Goltz (2001). Others' perspectives on the minimum amount of warning needed were evenly distributed over the other timeframes (Table 6). We further explore what people think they might do within these minimum timeframes in the section "Warning time versus actions".

Warning channel. People's preferred channel for receiving a warning was via mobile phone $(83 \%)$, consistent with data from Japan, where following the Gunma and Chiba prefecture earthquakes, most people received warnings via their mobile phones ( 89\%) (Nakayachi et al., 2019). ShakeAlert, the EEW system for the West Coast of the USA, is exploring options for delivery of warnings through mobile phones, including via smartphone apps and Wireless Emergency Alert (WEA) cell broadcasts (Given et al., 2018), both of which have been utilised in tests and real events such as the Ridgecrest earthquake (Cochrane and Husker, 2019). Similarly, the New Zealand National Emergency
Management Agency (NEMA) currently use cell broadcasts to send Emergency Mobile Alerts (EMA) as warnings about different hazard events (National Emergency Management Agency, n. d.a) and this channel could be a viable option for sending alerts.

Research highlights the importance of multiple channels to deliver warnings (Sorensen, 2000; McGinley et al., 2006; Wright et al., 2014). Accordingly, additional to mobile phones, there were also several other channels indicated by participants as useful, including television (47\%), radio (39\%), public announcement (33\%), and social media (31\%). Given the short warning timeframes for EEW, social media is probably the most challenging warning notification channel, however even with very short delivery timeframes, research into use of crowdsourced Twitter data (Steed et al., 2019) suggests that social media might present an opportunity for EEW. Platforms such as Twitter have been used effectively to deliver warnings during disaster events in Indonesia (Chatfield and Brajawidagda, 2013) with some crosscultural evidence suggesting that social media is used during disasters similarly in different countries (e.g. Australia and China (Kulemeka, 2014)). However, Twitter may be a useful post-alert messaging channel, to explain what occurred e.g. false alert, late alert, missed alert, inaccurate alert (McBride et al., 2020).

Message content. We suggested to participants that on receipt of an EEW alert they might receive the following message: "Earthquake early warning, strong shaking expected soon", along with the name of the agency issuing the warning. We then asked participants to indicate on a five-point scale how strongly they agreed or disagreed that certain types of information should also be included (Table 7). Participants supported the inclusion of three additional types of information in an earthquake warning message: (1) Information on additional geohazards that might occur such as tsunami or landslides; (2) further information about the earthquake that has occurred; and (3) guidance on what action to take.

Support for the inclusion of additional information about likely geohazards points to the need to integrate EEWs with other related hazards. Tsunami is particularly relevant, given the length of coastline in New Zealand and the potential for a near-shore tsunami to be generated, putting coastal communities at significant risk. Japan has integrated its earthquake and tsunami warnings into one system to provide a chain of information to users to which they can respond accordingly (Japan Meteorological Agency, 2019).

New Zealanders also had an appetite to receive further information about the earthquake itself (e.g., location and magnitude). Such data is currently provided via the GeoNet system via rapid post-earthquake notifications but could also be integrated into an EEW chain of alerts. Further information about an earthquake could potentially come after the initial warning as it does in Japan, either directly or by provision of a link as supported by $72 \%$ of participants.

Finally, participants suggested that an EEW message might also include some information about what actions to take in response to the alert. There has been debate about whether such information should be included in warning messages, as actions might differ depending on the context a person is in (Wood, 2018; Goltz et al., 2020). However short action messages may be useful as a reminder for action, providing that people are also familiar with these actions prior to receiving a warning (e.g., through education, training and exercises). Guidance messages for action are a crucial aspect of short warning messages to achieve an optimal behavioural response (Mileti and Sorensen, 1990; Mileti and Darlington, 1995; Potter, 2018). New Zealand's current guidance is to 'drop, cover and hold' (McBride et al., 2019); this message, or an associated image of this action if the 


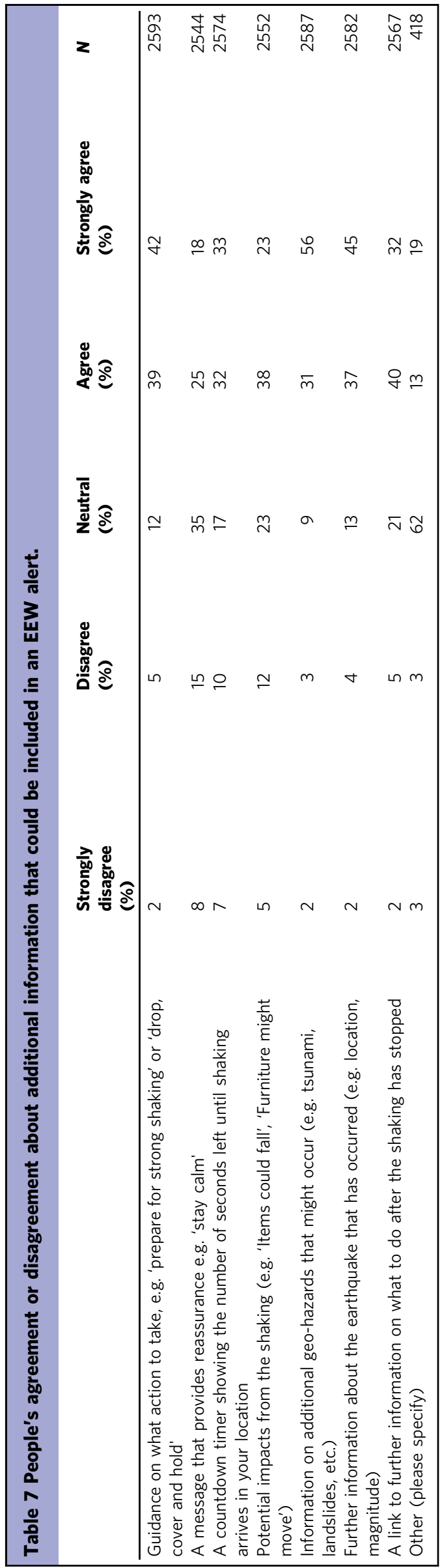

channel allows it, could be included in future EEW messages. A reminder about noticing whether the earthquake shaking is 'long or strong' could also help with rapid tsunami self-evacuations after the shaking.

Interestingly, there was less support for including a countdown timer in an alert (65\%), providing a description of potential impacts from the shaking $(60 \%)$, or including a reassuring messaging (e.g., "Stay calm"). While more participants than not liked the idea of using a countdown timer to know when shaking will begin, some felt that this might cause anxiety. Perhaps the same could be said of knowing what the potential impacts might be. Reassuring messages may also not be seen as useful by participants as reassurance may be better gained by a sense of control of knowing what is going to happen and what actions are needed in response; for example, action coping (i.e., coping with a threat by focusing on actions which can be taken rather than on the threat itself) increases protective behaviours for earthquakes (McIvor and Paton, 2007).

In terms of participants' free responses, several people $(n=9)$ suggested it was important to include information that notified people if it was a false alarm or if the event had ended, for example if the threat of shaking had passed. Additionally, 43 people cautioned that there should not be too much information in a message as there might be limited time available to read it all. The latter is an important point; initial EEW messages should be succinct given the short timeframes available for warnings. Recent research has identified, however, that longer mobile phone alerts can reduce the tendency for receivers to delay actions by searching for additional information, than if they receive shorter warning messages for imminent threats (Wood et al., 2017). The diversity of interest in information suggests that EEW should perhaps not be thought of as a single alert but a continuum of linked messages in which the first alert is the beginning of a chain of advice.

Intended responses to an EEW. We used an earthquake scenario to understand the anticipated responses to an EEW by New Zealand public survey participants. The scenario was based on the timing and nature of Gunma and Chiba earthquakes in Japan (Nakayachi et al., 2019), so that we could make comparisons with the public response from these two real earthquakes that activated Japan's EEW.

The scenario read as follows:

"It is Saturday evening at 8.30 p.m. An earthquake occurs somewhere near you, but you don't know the location of the earthquake or how big it is (the magnitude). The earthquake automatically triggers an earthquake early warning. You receive this warning as a mobile phone alert before shaking occurs. The alert says "Earthquake Early Warning. Strong shaking expected soon". You don't know how long you have before the shaking starts, or how strong the shaking will be in your location. However, you could assume with "strong shaking" it would be hard to walk, and there would be falling objects and moving furniture".

Participants were asked to think about where they were on the previous Saturday evening, so as to provide a real context from which to answer the questions. The scenario was set on a weekend evening so that most people would likely be inside at home, as per the events in Gunma and Chiba. Indeed, most stated that they were inside at home (77\%), or inside at another location such as a restaurant, bar, movie theatre, educational facility, or friend's house (17\%). Only a small proportion were outside $(2 \%)$, in a vehicle such as a car or bus (1\%), or in some other location $(3 \%)$. 
Table 8 Actions New Zealand survey participants thought they were "extremely likely" or "likely" to take on receipt of an EEW (with the two categories combined), compared with "what respondents did" in the Gunma and Chiba Earthquakes, Japan (Nakayachi et al., 2019, p. 7).

\begin{tabular}{|c|c|c|c|}
\hline & $\begin{array}{l}\text { New Zealand }(\%) \\
(N=2714)\end{array}$ & $\begin{array}{l}\text { Japan Study 1: Gunma } \\
(\%)(N=189)^{a}\end{array}$ & $\begin{array}{l}\text { Japan Study 2: Chiba } \\
(\%)(N=359)^{a}\end{array}$ \\
\hline \multicolumn{4}{|l|}{ Inactions } \\
\hline Do nothing/undertake no actions & 22 & 43 & 34 \\
\hline Cannot do anything & Not asked in NZ & 11 & 8 \\
\hline \multicolumn{4}{|l|}{ Motionless reactions } \\
\hline Stop and stay still, awaiting the shaking on the spot & 34 & 21 & 21 \\
\hline $\begin{array}{l}\text { Look for further information about the warning (e.g. check GeoNet, } \\
T V \text {, radio or mobile phone or talk to other people) }\end{array}$ & 67 & 21 & 24 \\
\hline Mentally prepare myself for the shaking & 91 & 16 & 25 \\
\hline \multicolumn{4}{|l|}{ Physical reactions } \\
\hline Tell other people the earthquake is coming & 84 & 6 & 9 \\
\hline Move nearby to where I think it is safe & 89 & 4 & 7 \\
\hline $\begin{array}{l}\text { Help others or act to protect others (e.g. children, other family, } \\
\text { friends, workmates) }\end{array}$ & 89 & 4 & 6 \\
\hline $\begin{array}{l}\text { Undertake safety actions (e.g. secure furniture, secure a potentially } \\
\text { dangerous piece of equipment, turn something off (e.g. gas fire), open } \\
\text { the door to secure the way out, put on clothes or shoes) }\end{array}$ & 67 & 4 & 5 \\
\hline $\begin{array}{l}\text { Take specific behaviours to protect myself on the spot (e.g. drop, } \\
\text { cover and hold, hold on to something, protect head, take cover under } \\
\text { the table, etc.) }\end{array}$ & 86 & 3 & 6 \\
\hline Slow down, pull over and stop car & 71 & 3 & 1 \\
\hline Go outside & 29 & 2 & 3 \\
\hline \multicolumn{4}{|l|}{ Not sure and other } \\
\hline No sure/cannot remember & Not asked in NZ & 2 & 1 \\
\hline Other & 30 & 2 & 2 \\
\hline
\end{tabular}

We asked participants to state how likely they would be to undertake a number of listed actions on receipt of an EEW. These anticipated actions aligned with real actions asked about in the Japan surveys (Nakayachi et al., 2019) but instead of using a yes/ no response, and to reflect the uncertainty associated with future intentions, participants were asked to select from options on a 5point scale from extremely unlikely to extremely likely.

The most likely intended action (i.e. "extremely likely" and "likely" combined) was a motionless reaction, where people said they would "mentally prepare for the shaking" (91\%) (Table 8). Sixteen percent of survey respondents in the Gunma earthquake and a quarter of people in the Chiba earthquake stated that this is what they did in response to an actual earthquake warning, showing rates of New Zealanders' intending to mentally prepare for the shaking is much higher than rates during an actual Japan EEW. Other intended motionless reactions by the New Zealand participants with high rates included "look for further information about the warning" (67\%) and "stop and stay still, awaiting shaking on the spot" (34\%). The proportion of people who suggested that they would "stop and stay still" aligns with previous data on observed behaviour during shaking (Prati et al., 2013; Lindell et al., 2016), and perhaps is a function of the high number of New Zealand participants who have experienced strong shaking previously (73\%). Both the reactions "look for further information" and "stop and stay still" were reported at lower levels for the Gunma and Chiba warnings.

We asked participants to provide free responses on the reasons why they thought it was "extremely likely" that they would undertake these motionless reactions. People suggested they might stay still for different reasons including because they were afraid, had done so in a past event (e.g., 2010-2011 Canterbury earthquakes), or because they were mentally preparing themselves for the impending shaking. The benefits of mentally preparing were articulated by respondents, many of whom suggested that a few seconds of mental preparedness could help with responding appropriately:

"Being able to mentally prepare for an earthquake beforehand would mean a clearer head when it actually occurs, and not fumbling around thinking of what to do."

There were some who articulated that while they might mentally prepare during the warning timeframe, they might only take an action once shaking starts:

"Giving myself mental preparation and not panicking is what I [would] do, if I had just a bit of time [to] prepare I would feel calmer and more likely to act quickly when the shaking actually started."

Looking for further earthquake information was linked to the desire to confirm the warning information, as highlighted in comments such as "to check and confirm the news". This is a common reaction to warning messages, and causes a delay in responding, referred to as 'milling' (Wood et al., 2017). The key way to shorten the duration of milling is to ensure that all elements of a warning message are included (Wood et al., 2015; Potter, 2018). Looking for further information is also linked with trust in the system (e.g., one person suggested they would seek information because, "I wouldn't trust the warning system to be providing me relevant information"). Trust in the information source is an important factor in interpretation and response (Mileti and Sorensen, 1990; Wogalter et al., 1999; Becker et al., 2019). Even with extremely short timeframes for EEW, looking for information appeared to be part of the process in determining what action to take (e.g., "...[look for] more information to make an informed decision on what to do"). 
Overall, participants were optimistic in their intentions to take physical action on receipt of an EEW. More than $80 \%$ of survey participants suggested it was extremely likely or likely they would move nearby to where they thought it would be safe (89\%), help others or act to protect others (89\%), take specific behaviours to protect themselves on the spot such as drop, cover, hold (86\%), or tell other people the earthquake is coming (84\%). Many also thought they would undertake safety actions (67\%). Reasons for taking such actions included a desire to protect themselves so that they were safe and survived shaking without injury or death. Some also had real-life experience of these actions (e.g., in the 2010-2011 Canterbury or 2016 Kaikoura earthquakes), or had practiced an exercise such as the ShakeOut drill (McBride et al., 2019; Vinnell et al., 2020). There was a particularly strong sense of responsibility for others, as seen in other earthquake contexts (Turner et al., 1986; Dooley et al., 1992; Edwards, 1993; Russell et al., 1995; McIvor and Paton, 2007; Becker et al., 2014), with participants wanting to warn others about the EEW and take action to protect other people, particularly children but also other family members, pets, friends, and vulnerable persons (e.g., disabled, elderly, sick).

The figures of intended physical reactions are at odds with actual numbers of people who undertook such responses in warnings in Japan. Less than $10 \%$ of survey participants from Gunma and Chiba undertook any physical actions in response to the earthquake warnings (Nakayachi et al., 2019). A large body of literature has demonstrated that intentions strongly but do not completely predict behaviour (Webb and Sheeran, 2006), although some evidence supports that people's intentions are acceptable proxies for behaviour (e.g., hurricane evacuation (Kang et al., 2007)).

Only $22 \%$ of participants thought it likely or extremely likely that they would do nothing in response to an EEW, a lower proportion than was seen in Japan (43\% Gunma, 34\% Chiba (Nakayachi et al., 2019)). There was an element of optimism from participants in that they thought the place they were in would be safe $(30 \%)$, which was also seen in Japan (25\% Gunma, 17\% Chiba). However, our respondents were more likely to believe that they would not have enough time to undertake actions before the shaking began (30\%) compared with Japan (5\% for both Gunma and Chiba). Japanese survey respondents were more likely to do nothing in response to an EEW because they expected the impending shaking to be of small intensity (Gunma 28\%; Chiba $38 \%$ ), despite alerts only being sent out when strong shaking is anticipated. This is in contrast with New Zealand participants where only $11 \%$ thought this might influence their decision to do nothing. This speaks to the Japanese experience of early warnings, where perhaps repeated experience of warnings has helped them understand that they can take action, but they often do not because of their optimism that the shaking will not be severe and they will be safe (Nakayachi et al., 2019). This effect of experience has implications for EEW education and training; countries developing new EEW systems might need more of a focus on helping people understand what actions can be taken in response to a warning within a short timeframe, while countries with an advanced system may need to focus on reducing optimism and normalisation biases (Weinstein, 1980; Mileti and O’Brien, 1992; Spittal et al., 2005; Mclvor et al., 2009).

Participants provided suggestions about other actions they might take instead of the listed options. Actions that differed from those already listed included check or save pets $(n=48)$ and assess tsunami risk/evacuate from a tsunami $(n=35)$. These comments speak to two issues not picked up in the current EEW literature. The first is that pets comprise part of the decision-making process for EEW action. This has been seen in events with longer fuse warnings such as evacuation for the 2017 Port Hill (New Zealand) fires (Squance et al., 2018) and is reinforced in the EEW context.
The second is that people may consider evacuating for a tsunami threat on seeing an EEW alert. For example, one participant who suggested it was extremely likely they would move to safety and go outside on receipt of a warning said they would do so, "Because of the danger and tsunami risk of where we are". As articulated in this instance, such evacuation may commence before shaking begins and people may move into an area that is dangerous during shaking, rather than protect themselves from shaking.

Warning time versus actions. Participants were invited to freely articulate what actions they thought they would take if they knew they had (a) $10 \mathrm{~s}$ or less of warning before earthquake shaking occurred, (b) 11-30 s of warning, (c) 31-60 s of warning, or (d) more than $60 \mathrm{~s}$ warning. Participants often provided multiple actions, and these were coded for each timeframe as 'First action', 'Second action', 'Third action', and 'Fourth action'. Actions were then graphed for the different timeframes (Fig. 1).

Participants were more likely to take no action or feel like they could not do anything for the shortest timeframe of $<10 \mathrm{~s}$. Similarly, for motionless reactions, people suggested that they were more likely to stay still and mentally prepare themselves if they thought they had $<10 \mathrm{~s}$ of warning than if they had a longer warning timeframe. Mental preparedness also occurred for some people as a primary action for up to $30 \mathrm{~s}$ of warning, and as a secondary action for timeframes of up to $60 \mathrm{~s}$ and over. Looking for further information was suggested as a first action if people felt they had $30 \mathrm{~s}$ or more available to them before shaking started.

In terms of physical reactions, protecting oneself was seen more of a first action to take and was more likely to be taken in the first $10 \mathrm{~s}$. The number of people suggesting that they would protect themselves as a primary action decreased the greater the warning time available and became predominantly a second, third, or fourth action. Undertaking safety actions had the opposite relationship, whereby these actions were more likely to be identified as a first action with $31-60+s$ warning and less likely at $10 \mathrm{~s}$ or less. Telling other people that the earthquake was coming increased over warning timeframes; it was predominantly a first/second action within a warning timeframe of $0-30 \mathrm{~s}$ and a second/third action with a warning timeframe of $30 \mathrm{~s}$ and over. Many people selected "move nearby to safety" as an action across all timeframes, as a first action up to $30 \mathrm{~s}$ and a second and third action from 31 to $60 \mathrm{~s}$ and over. Only a few participants selected the option of specifically going outside/evacuating for the warning timeframe of $<10 \mathrm{~s}$, but the desire to undertake this action increased with available time, as highlighted also by previous research in a California setting (Goltz, 2001).

Analysis of the data highlights that perceptions of the time available between a warning and shaking will likely influence people's responses to EEW. This has implications for decisions about whether information such as countdown timers, which show how many seconds there are before shaking begins in the receiver's location, should be included in alerts. People may be more likely to stop, mentally prepare, and take protective action if they believe they only have a short time before shaking starts. This was reinforced by many of the respondents' comments who suggested that for short warning timeframes they were extremely likely to undertake protective action because such actions were quick, easy, and provided the greatest benefit.

"Given [the] short window of opportunity, [you] need to take the steps that are most likely to have biggest impact";

"They are incredibly simple tasks that require very little time to do-I would be able to do these (send a message, move under a table, etc.) without knowing how imminent the shaking is.". 

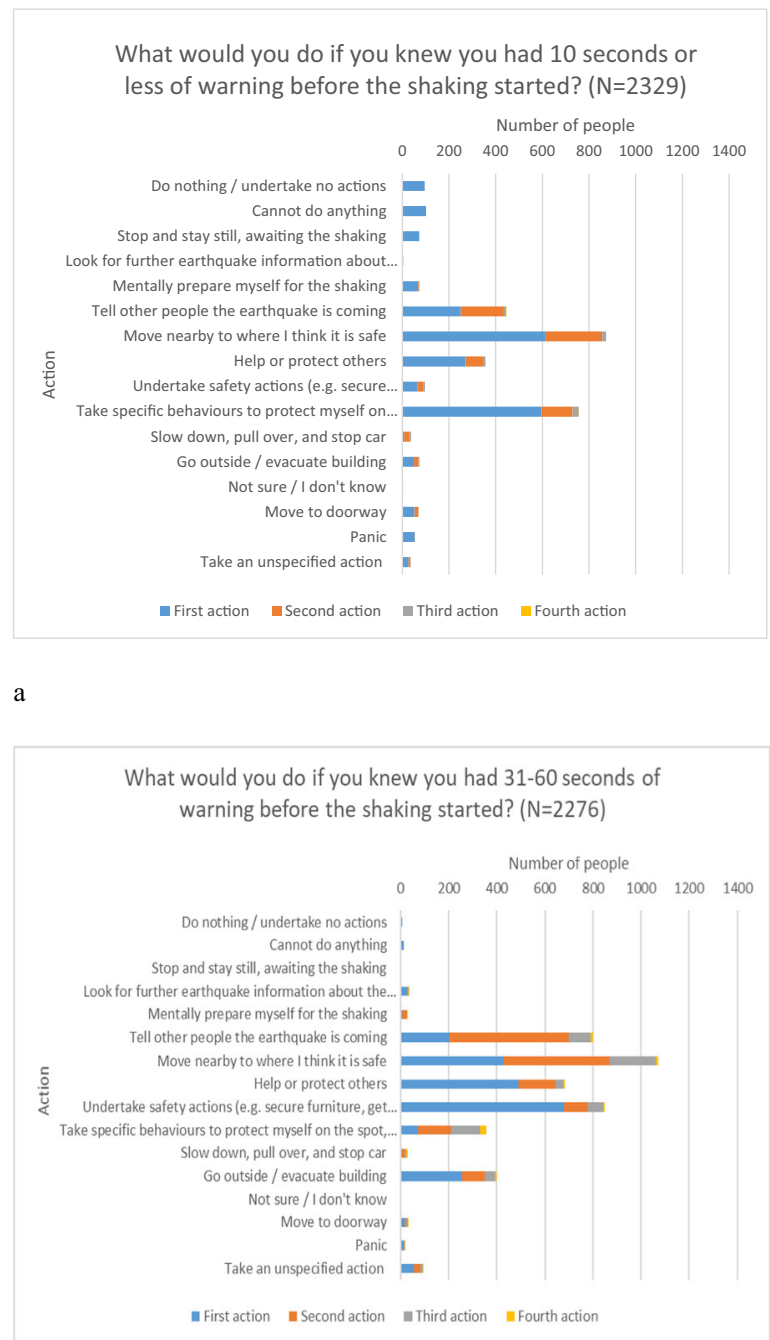

c

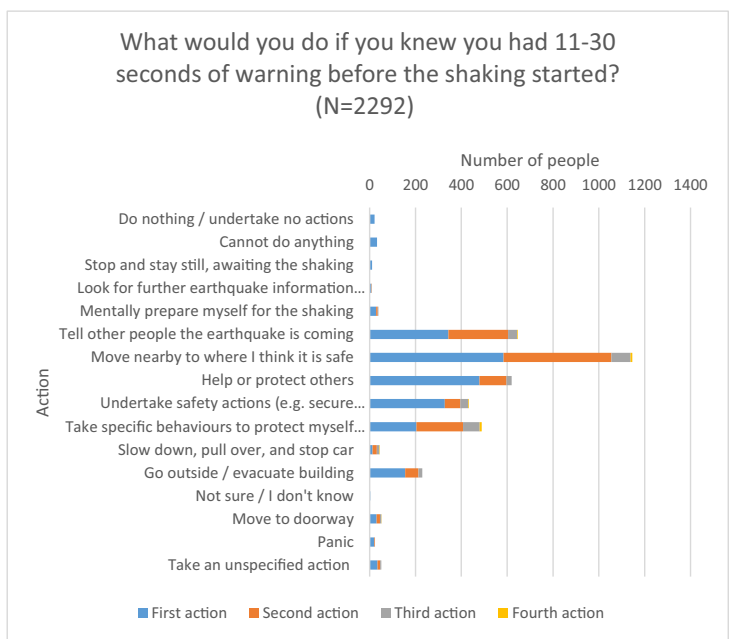

b

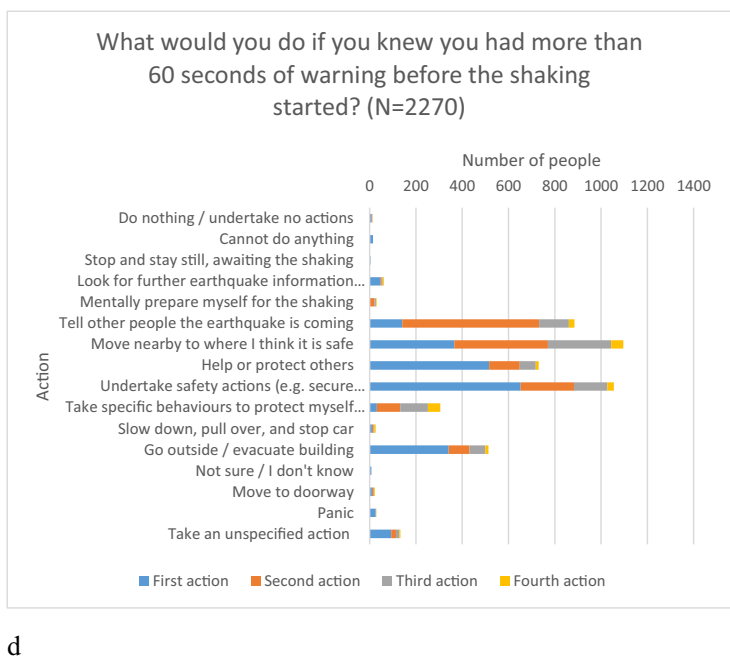

Fig. 1 Anticipated actions for different warning timeframes. Showing actions that participants said they would take if they knew they had a 10 s or less of warning before earthquake shaking occurred, b 11-30s of warning, c 31-60s of warning, or $\mathbf{d}$ more than 60s warning.

A belief that shaking will not start for many seconds more may increase people's desire to move around increasing potential for injury should the shaking arrive (Johnston et al., 2014). However, knowledge of a longer timeframe before shaking begins may also have a benefit of being able to take other safety actions, for example, securing furniture or dangerous equipment, turning off equipment, or evacuating earthquake-prone buildings (Santos-Reyes, 2019). It is possible that for longer warning timeframes there may be a lower intensity of shaking, thus reducing risk and perhaps the imperative to undertake safety actions, but this is not a given and is dependent on the location and nature of the fault rupture (Minson et al., 2018). Lower levels of shaking may not always occur with longer warning timeframes. Consequently, EEW developers and emergency managers need to consider what creates the most benefit: providing messages about the time available before shaking so people can take safety actions or a simple message about imminent strong shaking which prompts immediate protective action.

Additionally, given that participants potentially intended to take up to four actions on receipt of a warning, actions cannot be considered mutually exclusive but part of a sequence of actions. This is also seen in other studies such as analysis of human behaviour in CCTV footage for the 2011 Christchurch earthquake (Lambie et al., 2016).

\section{Conclusions}

We undertook a public survey in Aotearoa New Zealand to better understand whether EEW was considered useful and acceptable by the public, before New Zealand makes an investment in such technology. Overall, the public strongly supported the concept of EEW and intended to take action before shaking to protect themselves and others. However, while intended actions are often a good predictor of real action (e.g., hurricane evacuation (Kang et al., 2007)) one wonders whether this would hold true given intention-behaviour gaps in other contexts (e.g. in the health risk context or for pro-environmental behaviours). The low rates of physical protective actions undertaken in Japan for real EEWs suggest that the results presented here should be interpreted with caution. In addition to protective action, the majority of participants indicated that they would use early warning as an opportunity to mentally prepare themselves for imminent shaking. This finding aligns with mental preparedness for actual warning instances in Japan (Nakayachi et al., 2019), suggesting that the value of this aspect may be transferable across contexts.

Participants shared their perspectives on preferred system attributes which included having MM intensity thresholds of 5-6 (moderate-strong shaking); receipt of warnings via mobile phones (supported by other channels); and a diversity of 
messages. In addition to receiving a warning message about "strong shaking expected soon" participants wanted supporting information about (a) the earthquake that had occurred, (b) additional geohazards such as tsunami, and (c) what actions to take.

Given the timeframes available for EEW response, initial messages should prioritise information that informs effective action (Potter, 2018; Wood, 2018). For example, an initial alert might provide a short message such as "Earthquake early warning, strong shaking expected soon, drop cover hold" or "Earthquake early warning, strong shaking expected soon, take protective action" (the latter of which could be useful across different contexts). More work is needed around how best to convey and support this information (Sutton et al., 2020).

After shaking has occurred, another short message could be delivered to coastal areas who received the EEW, stating that if the earthquake shaking felt 'long or strong' then evacuate immediately in case of tsunami (as per official guidance from emergency management (National Emergency Management Agency, n.d.b)). Subsequent messages could provide links to further information about the earthquake that has just occurred, the impacts, and what to do. This information could come from the same source or channel, or from separate sources or channels, as long as this integration is identified and addressed, as exemplified in the JMA system (Japan Meteorological Agency, 2019).

People's anticipated actions on receipt of a warning differed over varying timeframes with people more likely to intend undertaking quicker and easier actions for shorter timeframes of $<10$ s (e.g., stop, mentally prepare, take protective action), and more likely to move to a nearby safe area, help others, look for more information, or take safety actions as timeframes increased. Mapping these actions out over time provides interesting insight into behaviours for short-fuse warnings and support for the idea that people likely need time to process the warning message and mentally prepare before acting (Wood et al., 2017).

Given that anticipated actions differed over varying timeframes, those developing EEW messaging should consider whether a priority is to focus on getting people to undertake quick protective actions or whether additional information like a countdown timer should be included to allow people to move around and undertake further safety actions. Given many alerts will only be received up to $10 \mathrm{~s}$ before shaking begins (Minson et al., 2018), it may be more realistic to focus public education on responses that are appropriate for that timeframe.

Finally, alert messages and educational and exercise initiatives should be aligned, to allow for consistency in understanding and response. Education and exercising comprises an important part of success in responding to an EEW. Educating people on how to respond to EEWs is an important component of the work being carried out for ShakeAlert in the USA (Cochran et al., 2018). Further, this suggestion is supported by differences between the Japan and New Zealand data; countries new to EEW might need to focus on training people how to respond to an EEW in the first instance, while countries with a mature system for which they have had personal experience receiving many EEWs, may need to focus on reducing optimism and normalisation biases.

In summary, our survey of the New Zealand public found support for having an EEW system, and optimism that such a system could be used for taking actions to assist safety and mental preparedness for earthquake shaking. We did not undertake a benefit-cost analysis or investigate benefits at a life-safety level; this could be an avenue for further research and has been undertaken by other countries (Hsiao et al., 2009; Cauzzi et al., 2016; Porter and Jones, 2018; Strauss et al., 2019; Bouta et al., 2020). Our recommendations for countries who are in the early stages of thinking about EEW, is to first take a step back and understand the social context within which the system is being developed. Our survey has contributed to this understanding for Aotearoa New Zealand. A better comprehension of social context will help develop warning system attributes, sources, channels and messages in ways that promote effective action, increasing the likelihood of such a warning reducing injuries and, potentially, fatalities.

\section{Data availability}

The data used in our analysis can be found in the attached Supplementary Information.

Received: 31 March 2020; Accepted: 18 September 2020; Published online: 04 November 2020

\section{References}

Allen R, Melgar D (2019) Earthquake Early Warning: advances, scientific challenges, and societal needs. Annu Rev Earth Planet Sci 47:361-388

Becker JS, Paton D, Johnston D et al. (2014) Societal influences on earthquake information meaning-making and household preparedness. Int J Mass Emergencies Disasters 32(2):317-352

Becker JS, Paton D, Johnston DM (2015) Communication of risk: a community resilience perspective. GNS Science Report 2015/66. GNS Science, Lower Hutt.

Becker JS, Potter SH, McBride SK et al. (2019) When the earth doesn't stop shaking: how experiences over time influenced information needs, communication, and interpretation of aftershock information during the Canterbury Earthquake Sequence, New Zealand. Int J Disaster Risk Reduction 34:397-411

Becker JS, Potter SH, Prasanna R, et al. (2020) Scoping the potential for Earthquake Early Warning in Aotearoa New Zealand: a sectoral analysis of perceived benefits and challenges. Int J Disaster Risk Reduct 101765. https://doi.org/ 10.1016/j.ijdrr.2020.101765

Bouta A, Ahn AYE, Bostrom A et al. (2020) Benefit-cost analysis for earthquake early warning in Washington State. Nat Hazards Rev 21(2). https://doi.org/ 10.1061/(ASCE)NH.1527-6996.0000346

Cauzzi C, Behr Y, Le Guenan T et al. (2016) Earthquake early warning and operational earthquake forecasting as real-time hazard information to mitigate seismic risk at nuclear facilities. Bull Earthq Eng 14:2495-2512

Chatfield AT, Brajawidagda U (2013) Twitter early tsunami warning system: a case study in Indonesia's natural disaster management. In: Sprague RH Jr (ed) Proceedings of the 46th annual Hawaii international conference on system sciences. IEEE Computer Society, pp. 2050-2060

Clinton J, Zollo A, Marmureanu A et al. (2016) State-of-the art and future of earthquake early warning in the European region. Bull Earthq Eng 14 (9):2441-2458. https://doi.org/10.1007/s10518-016-9922-7

Cochran ES, Aagaard BT, Allen RM et al. (2018) Research to improve Shake Alert earthquake early warning products and their utility, No. 2018-1131. US Geological Survey

Cochrane ES, Husker AL (2019) How low should we go when warning for earthquakes? Science 366(6468):957-958. https://doi.org/10.1126/science. aaz6601

Corbin J, Strauss A (2014) Basics of qualitative research: techniques and procedures for developing grounded theory, 4th edn Sage Publications, Thousand Oaks

Dooley D, Catalano R, Mishra S et al. (1992) Earthquake preparedness: predictors in a community survey. J Appl Soc Psychol 22:451-470

Dowrick DJ (1996) The modified Mercalli earthquake intensity scale: revisions arising from recent studies of New Zealand earthquakes. Bull N Z Natl Soc Earthq Eng 29:92-106

Dunn PT, Ahn AYE, Bostrom A et al. (2016) Perceptions of earthquake early warnings on the US West Coast. Int J Disaster Risk Reduct 20:112-122

Edwards ML (1993) Social location and self-protective behavior: implications for earthquake preparedness. Int J Mass Emergencies Disasters 11:293-303

Espinosa-Aranda JM, Cuéllar A, Rodríguez FH et al. (2011) The seismic alert system of Mexico (SASMEX): progress and its current applications. Soil Dyn Earthq Eng 31(2):154-162. https://doi.org/10.1016/j.soildyn.2010.09.011

Fujinawa Y, Noda Y(2013) Japan's earthquake early warning system on 11 March 2011: performance, shortcomings, and changes Earthq Spectra 29(Suppl 1):341-368

GeoNet (n.d. a) Felt Reports: GeoNet Geological hazard information for New Zealand. https://www.geonet.org.nz/data/types/felt. Accessed 27 Jan 2019

GeoNet (n.d b) Earthquake Intensity: simplified New Zealand MMI Scale. https:// www.geonet.org.nz/earthquake/intensity. Accessed 10 Apr 2018 
Given DD, Allen RM, Baltay AS et al. (2018) Revised technical implementation plan for the ShakeAlert system-an earthquake early warning system for the West Coast of the United States: U.S. Geological Survey Open-File Report 2018-1155. https://doi.org/10.3133/ofr20181155. [Supersedes USGS OpenFile Report 2014-1097]

Goltz JD (2001) TriNet policy studies and planning activities in real-time earthquake early warning: task 1 report. Survey of Potential Early Warning System Users, March 2001. UCLA/CPHDR. Los Angeles

Goltz JD, Park H, Nakano G et al. (2020) Earthquake ground motion and human behavior: using DYFI data to assess behavioral response to earthquakes. Earthq Spectra 8755293019899958

Haubrock S, Little C, McBride S et al. (2017) Keeping up with the citizenscollecting earthquake observations in New Zealand. In: Bregt, A., Sarjakoski, T., Lammeren, R. van, Rip, F. (Eds). Societal Geo-Innovation: short papers, posters and poster abstracts of the 20th AGILE Conference on Geographic Information Science. Wageningen University \& Research 9-12 May 2017, Wageningen, the Netherlands. ISBN 978-90-816960-7-4. Accessible through https://agile-online.org/index.php/conference/proceedings/proceedings-2017

Horiuchi Y (2009) Earthquake early warning hospital applications. J Disaster Res 4 (4):565-569. https://doi.org/10.20965/jdr.2009.p0237

Hoshiba M (2014) Review of the nationwide earthquake early warning in Japan during its first five years. In: Shroder, JF (ed.) Earthquake hazards, risk and disasters. Academic Press, pp. 505-529

Hsiao NC, Wu YM, Shin TC et al. (2009) Development of earthquake early warning system in Taiwan. Geophys Res Lett 36(5):L00B02, 1-5

Japan Meteorological Agency (2019) Earthquakes and Tsunamis-observation and disaster mitigation. Japan Meteorological Agency https://www.jma.go.jp/jma/ kishou/books/jishintsunami/en/jishintsunami_en.pdf Accessed 29 Jan 2020.

Johnson LA, Rabinovichi S, Kan GS et al. (2016) California early warning system benefit study. CSSC Publication 16-04, PEER Report No. 2016/06. PEERPacific Earthquake Engineering Centre

Johnston D, Standring S, Ronan K et al. (2014) The 2010/2011 Canterbury earthquakes: context and cause of injury. Nat Hazards 73:627-637

Kang JE, Lindell MK, Prater CS (2007) Hurricane evacuation expectations and actual behavior in Hurricane Lili. J Appl Soc Psychol 37:887-903

Kulemeka O (2014) How people affected by disaster use the internet: a study of Facebook usage during the 2014 Hazelwood Mine Fire in Victoria. Australas J Disaster Trauma Stud 18:51-56

Lambie E, Wilson T, Brogt E et al. (2016) Closed circuit television (CCTV) earthquake behaviour coding methodology: analysis of Christchurch Public Hospital video data from the 22 February Christchurch earthquake event. Nat Hazards 86:1-18. https://doi.org/10.1007/s11069-016-2735-9

Lindell M, Perry R (2012) The protective action decision model: theoretical modifications and additional evidence. Risk Anal 32:616-632

Lindell MK, Prater CS, Hao Che W et al. (2016) Immediate behavioural responses to earthquakes in Christchurch, New Zealand, and Hitachi, Japan. Disasters 40:85-111. https://doi.org/10.1111/disa.12133

McBride SK, Becker JS, Johnston DM (2019) Exploring the barriers for people taking protective actions during the 2012 and 2015 New Zealand ShakeOut drills. Int $J$ Disaster Risk Reduct 37, https://doi.org/10.1016/j. ijdrr.2019.101150

McBride SK, Bostrom A, Sutton J et al. (2020) Developing post-alert messaging for ShakeAlert, the earthquake early warning system for the West Coast of the United States of America. Int J Disaster Risk Reduct 50:101713

McGinley M, Turk A, Bennett D (2006) Design criteria for public emergency warning systems. In: Van de Walle B, Turoff M (eds) Proceedings of the 3rd international ISCRAM conference, New Jersey Institute of Technology, Newark, NJ, May 2006. pp. 154-163

McIvor D, Paton D (2007) Preparing for natural hazards: normative and attitudinal influences. Disaster Prev Manag 16:79-88

Mclvor D, Paton D, Johnston D (2009) Modelling community preparation for natural hazards: understanding hazard cognitions. J Pac Rim Psychol 3:39-46

Melnikovas A (2018) Towards an explicit research methodology: adapting research onion model for futures studies. J Futur Stud 23(2):29-44

Mileti DS, Darlington J (1995) Societal response to revised earthquake probabilities in the San Francisco Bay area. Int J Mass Emergencies Disasters 13:119-145

Mileti DS, O'Brien PW (1992) Warnings during disaster: normalizing communicated risk. Soc Probl 39:40-57

Mileti DS, Sorensen JH (1990) Communication of emergency public warnings-a social science perspective and state-of-the-art assessment. Oak Ridge National Laboratory

Minson SE, Meier M-A, Baltay AS et al. (2018) The limits of earthquake early warning: timeliness of ground motion estimates. Sci Adv 4:eaaq0504

Mulilis JP (1999) Gender and earthquake preparedness: a research study of gender issues in disaster management: Differences in earthquake preparedness due to traditional stereotyping or cognitive appraisal of threat?. Aust J Emerg Manag $14: 41$
Nakayachi K, Becker JS, Potter SH et al. (2019) Residents' reactions to earthquake early warnings in Japan. Risk Anal 39:1723-1740. https://doi.org/10.1111/ risa. 13306

National Emergency Management Agency (n.d. a) Emergency mobile alert. https:// www.civildefence.govt.nz/get-ready/civil-defence-emergency-managementalerts-and-warnings/emergency-mobile-alert. Accessed 18 Sept 2020

National Emergency Management Agency (n.d. b) Get Tsunami Ready. https:// www.civildefence.govt.nz/get-ready/get-tsunami-ready/. Accessed: 29 Jan 2020

Nishimae Y (2018) Earthquake early warning (EEW) system of the Japan Meteorological Agency (JMA). Presentation held at the Japan Meteorological Agency, Tokyo on 2018/5/7

NZ.Stat. (n.d.) Age and sex by ethnic group (grouped total responses), for census usually resident population counts, 2006, 2013, and 2018 Censuses (RC, TA SA2, DHB). http://nzdotstat.stats.govt.nz/wbos/Index.aspx?_ga $=2.222639576$ .2134273109.1575336012-1556407772.1575336012\#. Accessed 12 Jan 2020

Phillips DL, Clancy KJ (1972) Some effects of "social desirability" in survey studies. Am J Sociol 77:921-940

Porter KA, Jones JL (2018) How many injuries can be avoided in the HayWired scenario through earthquake early warning and drop, cover, and hold on?. In: Detweiler ST, Wein AM (eds) The HayWired earthquake scenario-Earthquake implications: U.S. Geological Survey Scientific Investigations Report, 2018. U.S. Geological Survey, Menlo Park

Potter SH (2018) Recommendations for New Zealand agencies in writing effective short warning messages. GNS Science Report 2018/02. GNS Science, Lower Hutt

Prati G, Saccinto E, Pietrantoni L et al. (2013) The 2012 Northern Italy earthquakes: modelling human behaviour. Nat Hazards 69:99-113

Russell LA, Goltz JD, Bourque LB (1995) Preparedness and hazard mitigation actions before and after two earthquakes. Environ Behav 27:744-770

Santos-Reyes J (2019) How useful are earthquake early warnings? The case of the 2017 earthquakes in Mexico City. Int J Disaster Risk Reduct 40:101148

Sorensen JH (2000) Hazard warning systems: review of 20 years of progress. Nat Hazards Rev 2000:119-125

Spittal MJ, McClure J, Siegert RJ et al. (2005) Optimistic bias in relation to preparedness for earthquakes. Australas J Disaster Trauma Stud (1): https:// www.massey.ac.nz/ trauma/issues/2005-1/spittal.htm

Squance H, Johnston DM, Stewart C et al. (2018) An integrative review of the 2017 Port Hill fires' impact on animals, their owners and first responders' encounters with the human-animal interface. Australas J Disaster Trauma Stud 22:97-108

Steed RJ, Fuenzalida A, Bossu R et al. (2019) Crowdsourcing triggers rapid, reliable earthquake locations. Sci Adv eaau9824. https://doi.org/10.1126/sciadv. aau9824

Strauss JA, Wein AM, Jones JL et al. (2019) The HayWired scenario-earthquake early warning forecast and potential hazard mitigation actions. In: Detweiler ST, Wein AM (eds) The HayWired earthquake scenario-societal consequences: U.S. Geological Survey Scientific Investigations Report 2017-5013R-W. U.S. Geological Survey, Menlo Park

Sutton J, Fischer L, James LE et al. (2020) Earthquake early warning message testing: visual attention, behavioral responses, and message perceptions. Int J Disaster Risk Reduction. https://doi.org/10.1016/j.idrr.2020.101664

Turner RH, Nigg JM, Heller-Paz D (1986) Waiting for disaster: earthquake watch in California. University of California Press, Berkeley

Vinnell LJ, Wallis A, Becker JS et al. Evaluating the ShakeOut drill in Aotearoa/ New Zealand: effects on knowledge, attitudes, and behaviour. Int J Disaster Risk Reduct 48:101721 https://doi.org/10.1016/j.ijdrr.2020.101721

Webb TL, Sheeran P (2006) Does changing behavioral intentions engender behavior change? A meta-analysis of the experimental evidence. Psychol Bull $132: 249$

Weinstein ND (1980) Unrealistic optimism about future life events. J Personal Soc Psychol 39:806-820

Wogalter MS, Kalsher MJ, Rashid R (1999) Effect of signal word and source attribution on judgments of warning credibility and compliance likelihood. Int J Ind Ergon 24:185-192

Wood M (2018) State-of-the-art knowledge of protective actions appropriate for earthquake early warning. Report prepared for the Cascadia Region Earthquake Workgroup (CREW). Nusura, Inc., Denver

Wood M, Bean H, Liu BF et al. (2015) Comprehensive testing of imminent threat public messages for mobile devices: updated findings. College Park (MD) National consortium for the study of terrorism and responses to terrorism. https://www.dhs.gov/sites/default/files/publications/WEA\%20-\% 20Comprehensive $\% 20$ Testing\%20 of\%20Imminent $\% 20$ Threat $\% 20$ Public\% 20Messages\%20for\%20Mobile\%20Devices\%20Updated\%20Findings.pdf. Accessed 17 Jun 2020

Wood MM, Mileti DS, Bean H et al. (2017) Milling and public warnings. Environ Behav 50:535-566. https://doi.org/10.1177/0013916517709561 
Wright KC, Leonard GS, Beatson A et al. (2014) Public alerting options assessment 2014 update. GNS Science Report 2014/66. GNS Science, Lower Hutt

\section{Acknowledgements}

The authors would like to acknowledge the following sources who provided funding for this project: Earthquake Commission (EQC) Biennial Research Funding Programme (EQC 18/750-Social and sector-based benefits of an Earthquake Early Warning System); QuakeCoRE a Tertiary Education Commission initiative (QuakeCoRE publication number 0533); and Kia manawaroa-Ngā Ākina o Te Ao Tūroa (Resilience to Nature's Challenge-National Science Challenge). We would also like to acknowledge Ben Payne and Maureen Coomer who helped with survey logistics, and our survey participants who filled in the Earthquake Early Warning survey. Any use of trade, firm, or product names is for descriptive purposes only and does not imply endorsement by the U.S. Government. We thank our USGS internal reviewers, Dr. Sarah Minson and Dr. Elizabeth Cochran, for their insights which greatly improved this article.

\section{Author contributions}

JSB developed the EEW survey, collected and analysed the data and wrote the manuscript. SHP assisted with developing the survey and contributed to the manuscript. LJV assisted with manuscript writing. KN assisted with survey development, analysed the survey data and contributed to the manuscript particularly with regard to articulating the Japanese context. Both SKM and DMJ assisted with manuscript writing and provided context for EEW in the United States.

\section{Competing interests}

The authors declare no competing interests.

\section{Additional information}

Supplementary information is available for this paper at https://doi.org/10.1057/s41599 020-00613-9.

Correspondence and requests for materials should be addressed to J.S.B.

Reprints and permission information is available at http://www.nature.com/reprints

Publisher's note Springer Nature remains neutral with regard to jurisdictional claims in published maps and institutional affiliations.

\section{(c) (1)}

Open Access This article is licensed under a Creative Commons Attribution 4.0 International License, which permits use, sharing, adaptation, distribution and reproduction in any medium or format, as long as you give appropriate credit to the original author(s) and the source, provide a link to the Creative Commons license, and indicate if changes were made. The images or other third party material in this article are included in the article's Creative Commons license, unless indicated otherwise in a credit line to the material. If material is not included in the article's Creative Commons license and your intended use is not permitted by statutory regulation or exceeds the permitted use, you will need to obtain permission directly from the copyright holder. To view a copy of this license, visit http://creativecommons.org/ licenses/by/4.0/.

(C) The Author(s) 2020 